\title{
MAJORIZATION UNDER CONSTRAINTS AND BOUNDS ON THE SECOND ZAGREB INDEX
}

\author{
Monica Bianchi, Alessandra Cornaro And Anna TORriero
}

\begin{abstract}
In this paper we present a theoretical analysis in order to establish maximal and minimal vectors with respect to the majorization order of particular subsets of $\Re^{n}$. Afterwards we apply these issues to the calculation of bounds for a topological descriptor of a graph known as the second Zagreb index. Finally, we show how our bounds may improve the results obtained in the literature, providing some theoretical and numerical examples.
\end{abstract}

Mathematics subject classification (2010): 05C35, 05C05, 05C50.

Keywords and phrases: Majorization, Schur-convex functions, graphs, second Zagreb index.

\section{REFERENCES}

[1] D. L. Alderson And L. LI, Diversity of graphs with highly variable connectivity, Physical Review E 75(046102) (2007), 1-11.

[2] B. C. ARnold, Majorization and Lorenz Order: A Brief Introduction, Lectures Notes in Statistics 43, Springer Verlag, Berlin, 1980.

[3] A. B. AtKinson, On the Measurement of Inequality, Journal of Economic Theory 2 (1970), 224-263.

[4] M. Bianchi AND A. Torriero, Some localization theorems using a majorization technique, Journal of Inequalities and Applications 5 (2000), 433-446.

[5] B. Bollobas ANd P. ERdös, Graphs of extremal weights, Ars Combinatoria 50 (1998), 225-233.

[6] K. Ch. Das, I. Gutman And B. Zhou, New upper bounds on Zagreb indices, J. Math. Chem. 46 (2009), 514-521.

[7] R. Grassi, S. STEFAni AND A. Torriero, Extremal Properties of Graphs and Eigencentrality in Trees with a Given Degree Sequence, The Journal of Mathematical Sociology 34-2 (2010), 115-135.

[8] I. Gutman And B. Furtula, Recent Results in the Theory of Randic, Mathematical Chemistry, Monograph No. 6, University of Kragujevac, Serbia, 2008.

[9] I. Gutman, B. Ruščćć, N. TRInAJstić AND C. F. Wilcox, Graph Theory and molecular orbitals. XII. Acyclic polyenes, J. Chem. Phys 62 (1975), 3399-3405.

[10] I. Gutman AND N. TRINAJSTić, Graph Theory and molecular orbitals. Total $\pi$-electron energy of alternant hydrocarbons, Chem. Phys. Lett. 17 (1972), 535-538.

[11] P. ERDős AND T. Gallai, Graphs with prescribed degrees of nodes, Hungarian Matematikai Lapok 11 (1960), 264-274.

[12] G. H. Hardy, E. Littlewood And G. Polya, Some simple inequalities satisfied by convex functions, Messanger of Math. $\mathbf{5 8}$ (1929), 145-152.

[13] J. Karamata, Sur une inégalité ré lative aux fonctions convexes (in French), Publ. Math. Univ. Belgrade 1 (1932), 145-148.

[14] L. Li, D. Alderson, J. C. Doyle And W. Willinger, Supplemental material: the $S(G)$ metric and assortativity, Internet Mathematics 2, 4 (2005a), 1-6.

[15] L. Li, D. Alderson, J. C. Doyle AND W. Willinger, Toward a theory of scalefree graphs: definitions, properties and implications, Internet Mathematics 2, 4 (2005b), 431-523.

[16] L. LovÁsz, Combinatorial Problems and Exercises (2nd ed.), Amsterdam: North-Holland, 1993.

[17] M. LU, H. LiU AND F. TIAn, The connectivity index, MATCH Communications in Mathematical and Computer Chemistry 51 (2004), 149-154. 
[18] A. W. Marshall And I. Olkin, Inequalities: Theory of Majorization and Its Applications, Academic Press, London, 1979.

[19] S. Nikolić, G. KovačEvić, A. MiličEvić and N. Trinajstić, The Zagreb indices 30 years after, Croat. Chem. Acta. 76 (2003), 113-124.

[20] C. T. PAN, A Vector Majorization Method for Solving a Nonlinear Programming Problem, Linear Algebra and its Applications 119 (1989), 129-139.

[21] I. SCHUR, Über ein Klass von Mittelbindungen mit Anwendungen auf Determinantentheorie, Sitzer. Berl. Math. Ges. 22 (1923), 9-20.

[22] P. TArazaga, Eigenvalue Estimate for Symmetric Matrices, Linear Algebra and its Applications 135 (1990), 171-179.

[23] P. TARAZAga, More Estimate for Eigenvalues and Singular Values, Linear Algebra and its Applications 149 (1991), 97-110.

[24] R. Todeschini And V. Consonni, Handbook of Molecular Descriptor, Wiley-VHC, Weinheim, 2000.

[25] Z. YAn, H. LiU AND H. LiU, Sharp bound for the second Zagreb index of unicyclic graphs, Journal of Mathematical Chemistry 42, 3 (2007), 565-574.

[26] Q. ZHAO, S. LI, Sharp bounds for the Zagreb indices of bicyclic graphs with k-pendant nodes, Discrete Applied Mathematics 158, 17 (2010), 1953-1962. 